\title{
Cetuximab promotes SN38 sensitivity via suppression of heat shock protein 27 in colorectal cancer cells with wild-type $R A S$
}

\author{
TAKASHI ISHIDA ${ }^{1}$, YOSHIYUKI ISHII ${ }^{2}$, MASASHI TSURUTA ${ }^{1}$, KOJI OKABAYASHI $^{1}$, \\ SHINGO AKIMOTO $^{1}$, KAORU KOISHIKAWA ${ }^{1}$, HIROTOSHI HASEGAWA ${ }^{1}$ and YUKO KITAGAWA ${ }^{1}$ \\ ${ }^{1}$ Department of Surgery, Keio University School of Medicine, Shinanomachi 35, Shinjuku-ku, Tokyo 160-8582; \\ ${ }^{2}$ Department of Surgery, Kitasato University Kitasato Institute Hospital, Shirokane 1-9-5, Minato-ku, Tokyo 108-8642, Japan
}

Received February 12, 2017; Accepted June 6, 2017

DOI: $10.3892 /$ or.2017.5734

\begin{abstract}
Combination treatment with cetuximab and CPT-11 produces beneficial and synergistic effects in wild-type $R A S$ metastatic colorectal cancer (mCRC) patients. However, the mechanism underlying this synergism is not yet understood. We examined whether cetuximab had a synergistic effect with CPT-11 and its active metabolite, SN38, and examined the molecular mechanism of the synergism between cetuximab and SN38 in CRC cells with various mutational status. We hypothesized that cetuximab promotes sensitivity to SN38 via suppression of heat shock protein 27 (HSP27), a protein involved in multidrug resistance through blocking the Janus kinase (JAK)/signal transducer and activator of transcription (STAT) signaling pathway, which is associated with chemosensitivity. Four human CRC cell lines with different $R A S$ and $B R A F$ mutational status were used. Expression levels of HSP27 protein correlated with SN38 sensitivity in these cell lines $(\mathrm{R}=0.841, \mathrm{P}=0.159)$. Exposure to cetuximab and various concentration of AG490, an inhibitor of JAK2, STAT3 and HSP27 protein levels, except in the KRAS G12V mutant line, SW620. A synergistic effect of cetuximab in combination with SN38 was observed in $R A S$ and $B R A F$ wild-type cells (here, Caco2), but not in the three other RAS- or BRAFmutated cell lines. These results indicate that cetuximab may promote sensitivity to SN38 via suppression of HSP27 through blocking the JAK/STAT pathway in Caco2 cells. The mutational status of numerous downstream effectors, such as $R A S$ and $B R A F$, is important in mono- or combination therapy with cetuximab. In conclusion, cetuximab may promote SN38 sensitivity via suppression of HSP27, through blocking the JAK/STAT signaling pathway, and shows synergistic effects when combined with SN38 in wild-type RAS CRC cells.
\end{abstract}

Correspondence to: Professor Yoshiyuki Ishii, Department of Surgery, Kitasato University Kitasato Institute Hospital, Shirokane 1-9-5, Minato-ku, Tokyo 108-8642, Japan

E-mail: yoshi6671@me.com

Key words: heat shock protein 27, SN38, cetuximab, STAT3, colorectal cancer

\section{Introduction}

Colorectal cancer (CRC) is one of the most serious types of cancer worldwide, in terms of both morbidity and mortality. Despite improvements in medical therapies, the efficacy of chemotherapy has reached a plateau and the 5-year survival rate of patients with untreated metastatic CRC (mCRC) is still below $10 \%$, and the underlying molecular basis remains to be clearly defined (1). Cancer cells often exhibit intrinsic resistance to chemotherapeutic agents, or develop resistance over time with treatment. The lack of responsiveness to chemotherapy is an important problem that needs to be resolved.

Cetuximab, a chimeric monoclonal antibody targeting the epidermal growth factor receptor (EGFR), has markedly improved the prognosis in patients with metastatic CRC (mCRC) who harbor wild-type $K R A S$ and $B R A F$ in their tumors (1-4). Furthermore, new findings regarding $R A S$ (NRAS) mutations can further assist in predicting the therapeutic effects of anti-EGFR antibody therapy (5-7). CPT-11, one of the major cytotoxic agents in mCRC, is converted into an active metabolite, SN38, which then acts as a topoisomerase I inhibitor. Several studies have shown synergism between cetuximab and DNA-damaging agents, such as CPT-11, in vitro and in vivo $(8,9)$. Although cetuximab may enhance the tumor response to some chemotherapeutic agents, including CPT-11 (10-12), the mechanism underlying this synergism remains unclear.

Mammalian heat shock proteins (HSPs) are known to be molecular chaperones in protein-protein interactions, acting as anti-apoptotic proteins and contribute to cell survival (13). HSPs have been classified into four major families, based on their molecular weights: HSP90, HSP70, HSP60 and 'small' HSPs (15-30 kDa), including HSP27 (14). Their expression can contribute to the malignant properties of cancer cells, including tumorigenicity, treatment resistance and apoptosis inhibition (14-18). Recently, HSP27 has been identified as a treatment target for several cancers, and clinical trials using an antisense oligonucleotide, OGX427, which inhibits HSP27 expression, have been performed in patients with prostate, bladder, ovarian, breast and non-small cell lung cancer, but not CRC (19). The therapy has been reported to be feasible and effective. In previous studies, we showed that HSP27 might 
Table I. Mutation status of colon cancer cell lines.

\begin{tabular}{lcccc}
\hline & Caco2 & WiDR & SW480 & SW620 \\
\hline$R A S$ & Wild-type & Wild-type & KRAS mutation & KRAS mutation \\
(Codon G13D) & (Codon G12V) \\
BRAF & Wild-type & Exon 15 (V600E) & Wild-type & Wild-type \\
\hline
\end{tabular}

Authentication of all cell lines was performed by investigating RAS mutation status of each cell line using PCR method. The mutational status of BRAF for a subset of the cell lines was obtained from previous reports $(34,35)$.

contribute to resistance to 5-fluorouracil in CRC, in vitro and in vivo (20-22). It has also been reported that HSP27 expression is involved in resistance to CPT-11 and doxorubicin in vitro $(23,24)$. HSP27 is also believed to be involved in multidrug resistance (25-27). Thus, we considered that cetuximab might promote sensitivity to CPT-11 and SN38 via suppression of HSP27.

The Janus kinase (JAK)/signal transducer and activator of transcription (STAT) signaling pathway and, in particular, STAT3, which is a transcription factor, are known to have oncogenic potential $(28,29)$. In CRC cells, activated STAT3 causes resistance to CPT-11 and inhibition of STAT3 strongly enhances the cytotoxic action of CPT-11 (30,31). STAT3 activation in CRC patients is also associated with adverse clinical outcomes, supporting its potential roles as a prognostic biomarker and/or a therapeutic target (32). Furthermore, STAT3 has been reported to regulate HSP27 in breast epithelial cells (33).

We hypothesized that cetuximab might promote sensitivity to CPT-11 and SN38, via suppression of HSP27 through blocking of the JAK/STAT signaling pathway. The aim of the present study was to assess whether cetuximab promoted SN38 sensitivity, and to elucidate the molecular mechanism of the change in SN38 sensitivity caused by cetuximab in CRC cells with various mutational statuses.

\section{Materials and methods}

Drugs, colorectal cancer cell lines and cell culture conditions. Cetuximab (2 mg/ml) and SN38, the active metabolite of CPT-11, were kindly provided in powder form by Merck Laboratories (Darmstadt, Germany) and Yakult Honsha Co., Ltd. (Tokyo, Japan), respectively. SN38 was dissolved in dimethyl sulfoxide (DMSO) to a final concentration of $10 \mathrm{mM}$. For in vitro experiments, stock solutions of drugs were diluted in phosphate-buffered saline (PBS).

We used four human CRC cell lines: Caco2, WiDR, SW480 and SW620. They were cultured in Dulbecco's modified Eagle's medium ((DMEM; Gibco, Charlestown, MA, USA), supplemented with $10 \%$ fetal bovine serum (FBS) and $1 \%$ penicillin/streptomycin. Cells were cultured at $37^{\circ} \mathrm{C}$ in $5 \% \mathrm{CO}_{2}$. Authentication of all cell lines was confirmed by investigating the RAS mutation status of each cell line using a polymerase chain reaction (PCR)-based method (conducted by SRL, Co., Tokyo, Japan). The mutational status of BRAF for cell lines was obtained from previous reports $(34,35)$. The results are summarized in Table I.
Proliferation and cytotoxicity assays. We conducted two experiments. One was to determine cetuximab sensitivity, while the other investigated the combined effects of SN38 and cetuximab or SN38 and AG490, an inhibitor of JAK2, instead of cetuximab. Here, $5 \times 10^{3}$ cells/well were seeded in 96-well plates. Then, tumor cells were treated with 1, 10 and $100 \mu \mathrm{g} / \mathrm{ml}$ cetuximab or a fixed cetuximab concentration of $10 \mu \mathrm{g} / \mathrm{ml}$ with SN38 or a fixed AG490 concentration of $40 \mu \mathrm{M}$ with SN38 concentrations ranging from 0.01 to $30 \mu \mathrm{g} / \mathrm{ml}$ for $48 \mathrm{~h}$, followed by overnight incubation in serum-free medium. For cetuximab/SN38 or AG490/SN38 co-treatment experiments, cells were pretreated with cetuximab or AG490 for $15 \mathrm{~min}$ before the SN38 addition. Cell viability was evaluated by the reduction of methylthiazol tetrazolium to formazan $(0.5 \mathrm{mg} / \mathrm{ml})$. The absorbance of each well was measured at 540 and $600 \mathrm{~nm}$ using a microplate spectrophotometer (Immuno Reader; Nalgen Nunc International, Rochester, NY, USA). Viability was assessed as the percentage of viable cells compared with untreated cells (100\% viable). The assessment was based on three independent experiments.

Western blot analysis. Whole-cell extracts (20 $\mu \mathrm{g} / \mathrm{lane})$ were electrophoresed through $7.5 \%$ sodium dodecyl sulfate polyacrylamide gels (Bio-Rad Laboratories, Hercules, CA, USA) and were transferred to an Immuno-Blot polyvinylidene fluoride membrane (Bio-Rad Laboratories). The membranes were blocked for $1 \mathrm{~h}$ in PBS (Gibco-BRL) with $0.5 \%$ Tween-20 (PBS-T) and 5\% non-fat dry milk at room temperature, then incubated at $4^{\circ} \mathrm{C}$ overnight with anti-human HSP27 mouse monoclonal antibody (1:2,000; G3.1; Lab Vision Corp., Fremont, CA, USA), anti-human $\beta$-actin mouse monoclonal antibody (1:5,000; AC74; Sigma-Aldrich, St. Louis, MO, USA), and anti-human STAT3 mouse monoclonal antibody (1:200; C-20; Santa Cruz Biotechnology, Santa Cruz, CA, USA). The membranes were incubated for $30 \mathrm{~min}$ with horseradish peroxidase-conjugated anti-mouse immunoglobulin $\mathrm{G}$ (IgG) (1:2,500; Promega Corp., Madison, WI, USA). Proteins were detected using the ECL-Plus reagent (GE Healthcare Life Sciences, Little Chalfont, UK) according to the manufacturer's protocol. Each experiment was performed in triplicate. AG490 (Abcam, Cambridge, UK), JAK/STAT and a JAK2 inhibitor were reconstituted in DMSO and stored at $-20^{\circ} \mathrm{C}$ until used.

Statistical analysis. Data are reported as means \pm standard deviation. Statistical analyses were performed using the Student's t-test or the Mann-Whitney U test. $\mathrm{P}<0.05$ were considered to indicate a statistically significant difference. 

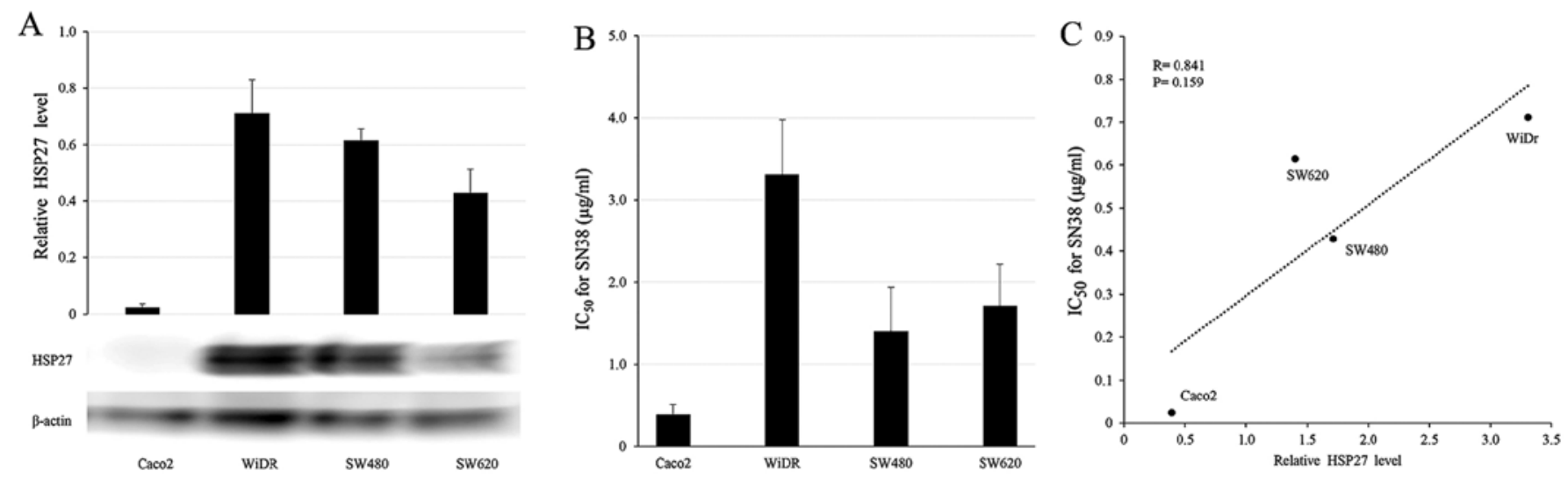

Figure 1. Heat shock protein 27 (HSP27) levels and SN38 sensitivity $\left(\mathrm{IC}_{50}\right)$ in colorectal cancer cell lines. (A) HSP27 protein levels in the cell lines were estimated by densitometry of western blots, standardized with $\beta$-actin levels. (B) SN38 sensitivity was estimated by the drug concentrations that caused 50\% growth inhibition vs. the control $\left(\mathrm{IC}_{50}\right)$. (C) Correlations between $\mathrm{HSP} 27$ protein levels and $\mathrm{IC}_{50}$ values for SN38 were evaluated in colorectal cancer cell lines by regression analysis.

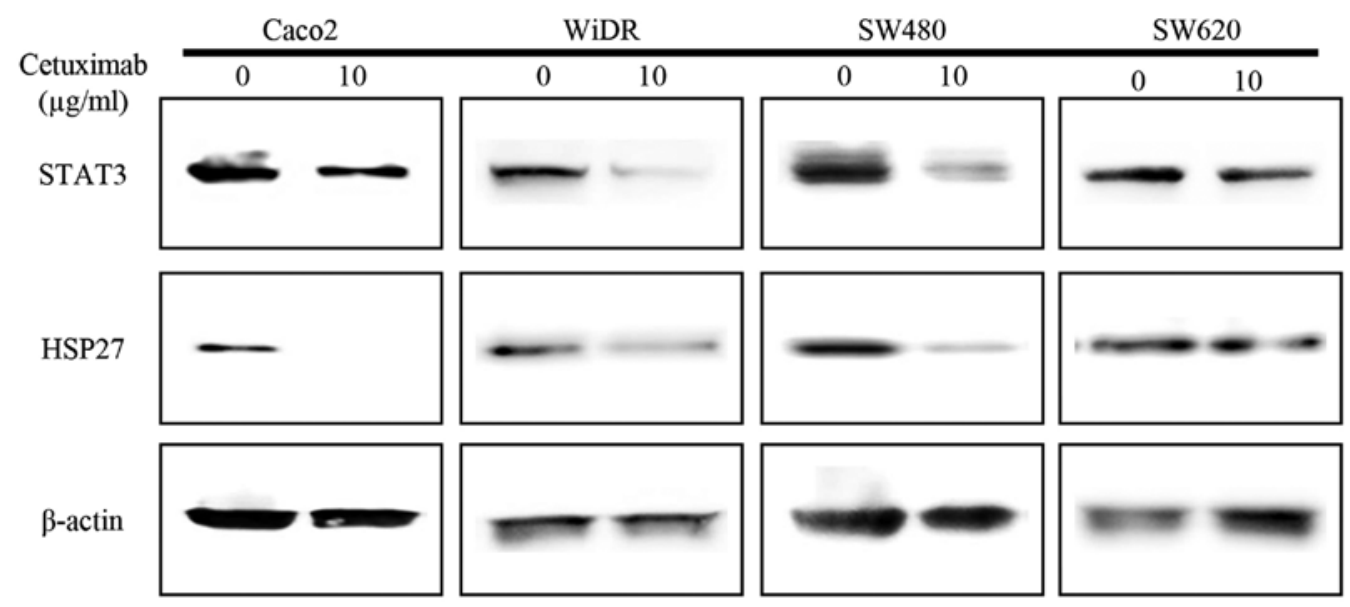

Figure 2. HSP27 downregulation with cetuximab exposure. Western blot analysis of the four colorectal cancer (CRC) cells treated with $10 \mu \mathrm{g} / \mathrm{ml}$ cetuximab for $24 \mathrm{~h}$. STAT3 protein was expressed constitutively in the four CRC cells with no cetuximab exposure. Levels of HSP27 and STAT3 were markedly downregulated in SW480 and Caco2 cells.

\section{Results}

$R A S$ and BRAF mutation status. The mutation status of each CRC cell line is shown in Table I. KRAS and NRAS mutations, which predict the efficacy of cetuximab treatment, were not detected in Caco2 or WiDR. However, the G13D and G12V $K R A S$ mutations were detected in SW480 and SW620, respectively. The exon 15 mutation in $B R A F$ was detected only in WiDR. From these results, Caco2 was selected as the 'positive' control because it had no mutation in KRAS, NRAS, or BRAF. WiDR, SW480 and SW620 were used as 'negative' controls because of $K R A S$ or $B R A F$ mutations.

Expression of HSP27 in CRC cell lines. Western blot analysis was conducted to determine HSP27 protein levels in the four CRC cell lines (Fig. 1A). WiDR, SW480 and SW620 cells showed high HSP27 protein levels and relative resistance to SN38, whereas Caco2 showed a low level of HSP27 protein and high sensitivity to SN38 (Fig. 1B). The HSP27 protein levels tended to correlate with the concentration of SN38, resulting in a $50 \%$ growth inhibition, but the results were not significant $\left(\mathrm{IC}_{50}\right.$; Fig. $1 \mathrm{C} ; \mathrm{R}=0.841$, $\mathrm{P}=0.159$ ).

HSP27 downregulation by exposure to cetuximab. HSP27 and STAT3 levels with exposure to cetuximab in the four CRC cells were evaluated by western blotting. STAT3 protein was expressed constitutively in the four CRC cell lines with no exposure to cetuximab. Levels of HSP27 and STAT3 were greatly downregulated in Caco2, WiDR and SW480 cells with exposure to $10 \mu \mathrm{g} / \mathrm{ml}$ cetuximab for $24 \mathrm{~h}$ vs. untreated cells. However, SW620 cells showed no significant difference in the expression of HSP27 or STAT3 with cetuximab exposure (Fig. 2).

Proliferation assay using cetuximab in CRC cell lines. Cell proliferation was assessed $48 \mathrm{~h}$ after exposure to cetuximab alone using the MTT assay. As shown in Fig. 3, little cytotoxic effect of cetuximab treatment (concentrations from 1 to $100 \mu \mathrm{g} / \mathrm{ml}$ ) was observed in WiDR, SW480 or SW620 cells. However, the proliferation of Caco2 cells was suppressed according to cetuximab concentration. 


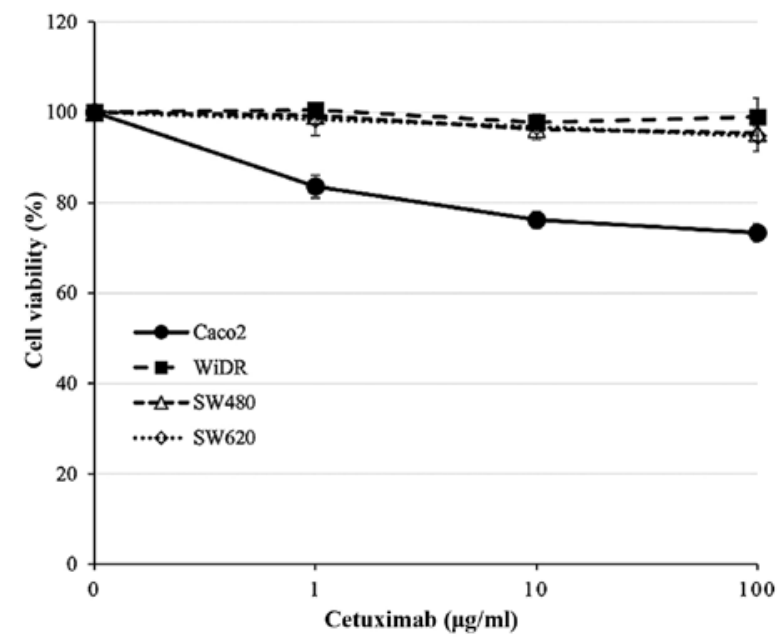

Figure 3. Cytotoxic effect of cetuximab treatment. Colorectal cancer cells were treated with various concentrations of cetuximab for $48 \mathrm{~h}$. Cytotoxicity was determined using the MTT assay, assessed by the percentage of living cells.

Cytotoxic effect of cetuximab in combination with SN38 in CRC cell lines. The cytotoxic effects of cetuximab in combination with SN38 were examined. CRC cells were treated with serial concentrations of SN38 (from 0.01 to $30 \mu \mathrm{g} / \mathrm{ml}$ ) in the presence or absence of cetuximab. Combined drug effects were evaluated in the four CRC cell lines. Fig. 4 shows representative effects of the cetuximab and SN38 combination. Treatment of $\mathrm{Caco} 2$ cells with $10 \mu \mathrm{g} / \mathrm{ml}$ cetuximab plus various concentrations of SN38 enhanced the cytotoxic effects significantly, depending on the SN38 concentration, compared with treatment with SN38 alone (Fig. 4A; $\mathrm{P}=0.04$ ). However, there was no significant combination effect in the three other cell lines (Fig. 4B-D). The addition of cetuximab (at a concentration causing $\sim 20 \%$ inhibition) reduced the $\mathrm{IC}_{50}$ value of SN38 from 0.52 to $0.31 \mu \mathrm{g} / \mathrm{ml}$ (40\% reduction) in Caco2. These results suggest a synergistic effect of cetuximab and SN38 in Caco2 cells.

HSP27 downregulation by exposure to AG490. Western blot analyses showed a concentration-dependent decrease in the levels of STAT3 and HSP27 at $24 \mathrm{~h}$ after AG490 (JAK2 inhibitor) exposure in Caco2, SW480 and WiDR cells. STAT3 and HSP27 were almost undetectable with $160 \mu \mathrm{M}$ AG490 in these three cell lines. However, no significant decrease in the levels of STAT3 or HSP27 was observed in SW620 cells (Fig. 5).

Cytotoxic effect of AG490 in combination with SN38 in Caco2 cells. The cytotoxic effects of AG490, in combination with SN38, were examined. Cell proliferation was assessed $48 \mathrm{~h}$ after exposure to AG490 alone using the MTT assay. Fig. 6A shows that the proliferation of Caco2 cells was suppressed based upon the AG490 concentration. Caco2 cells were treated with serial concentrations of SN38 (from 0.3 to $3.0 \mu \mathrm{g} / \mathrm{ml}$ ) in the presence or absence of a fixed AG490 concentration $(40 \mu \mathrm{M})$ for $48 \mathrm{~h}$. Fig. $6 \mathrm{~B}$ shows the representative effects of the AG490 and SN38 combination. Treatment of Caco2 cells with $40 \mu \mathrm{M}$ AG490 plus the various concentrations of SN38 enhanced the cytotoxic effects comparable to that the effect with cetuximab plus SN38; however, the result was not significantly better than that obtained with treatment with SN38 alone (Fig. 6B; P=0.11).
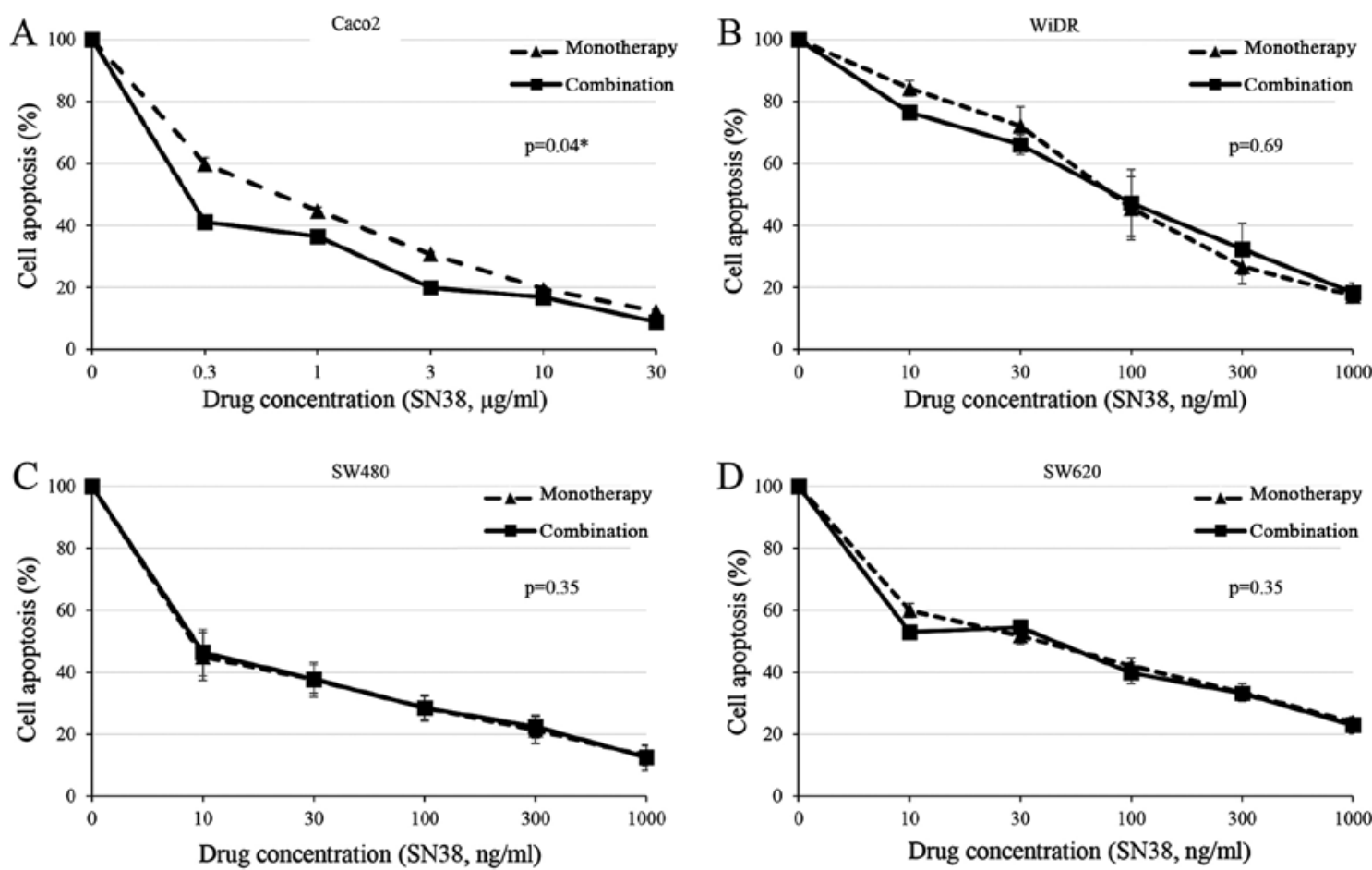

Figure 4. Combined effects of cetuximab and SN38 in CRC cell lines. (A) Caco2, (B) WiDR, (C) SW480 and (D) SW620 were incubated with various concentrations of SN38 in the presence or absence of $10 \mu \mathrm{g} / \mathrm{ml}$ cetuximab for $48 \mathrm{~h}$. Cell viability was then determined with the MTT assay. Data are expressed as percent change (means $\pm \mathrm{SD}$ ) vs. the control. ${ }^{\mathrm{P}}<0.05$, vs. SN38 alone-treated cells. 
A

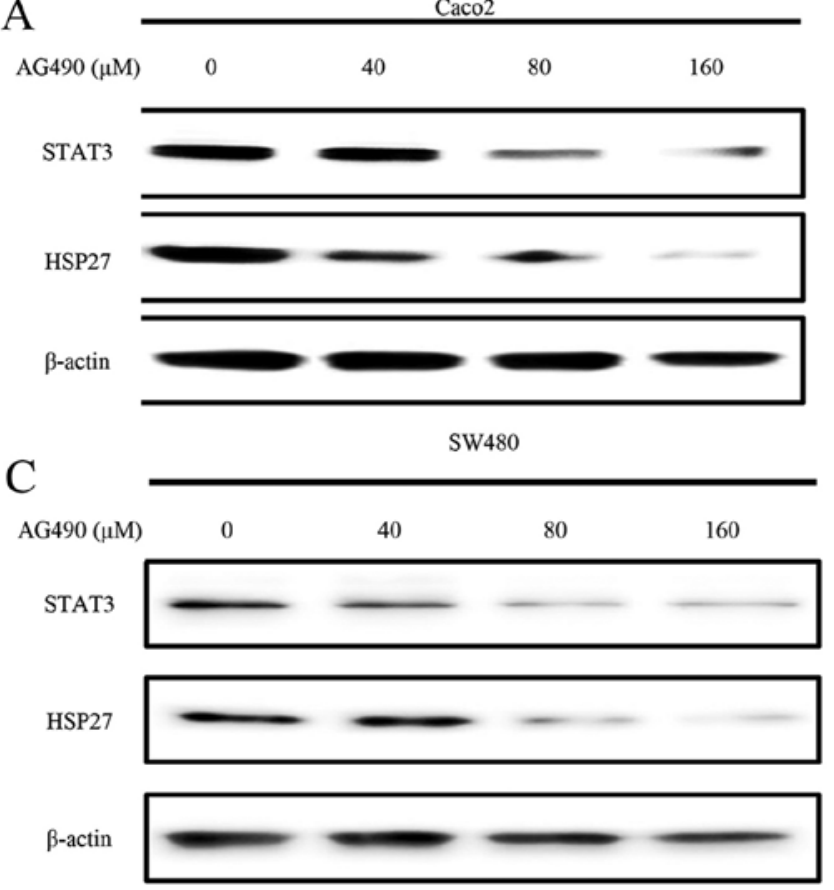

B

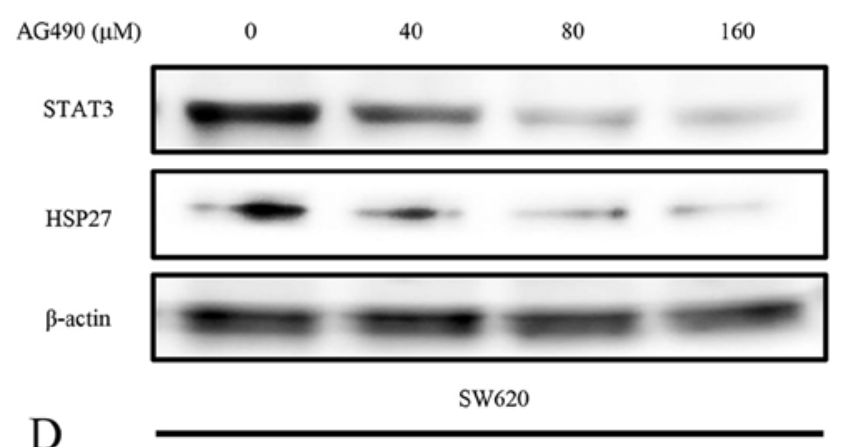

D $\mathrm{AG} 490(\mu \mathrm{M})$ $0 \quad 40$ $40 \quad 80$ 160 STAT3

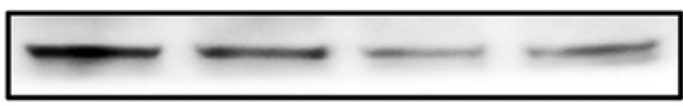

HSP27

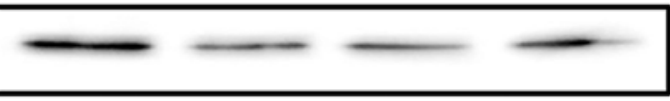

$\beta$-actin

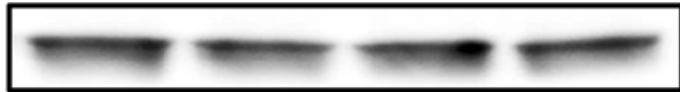

Figure 5. HSP27 downregulation by exposure to AG490. Western blot analysis of (A) Caco2, (B) WiDR, (C) SW480 and (D) SW620 cells treated with various concentrations of AG490 for $24 \mathrm{~h}$. AG490 induced concentration-dependent decrease in HSP27 and STAT3 protein levels, respectively.
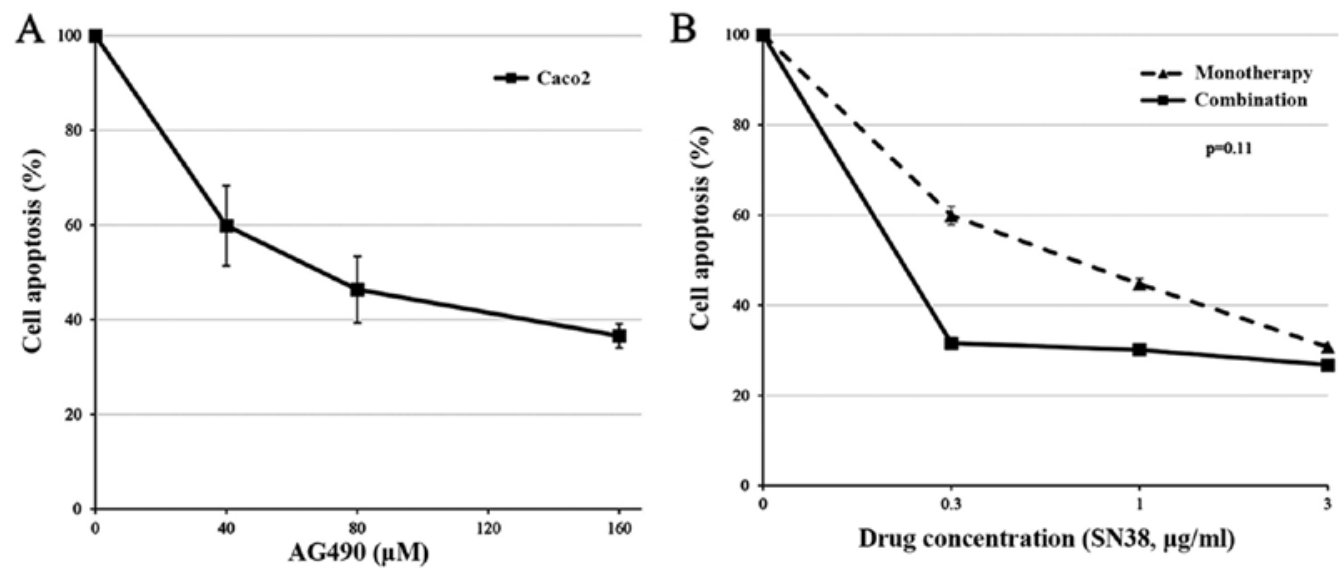

Figure 6. Cytotoxic effect of AG490 alone (A) and the combined effect of AG490 and SN38 (B) for 48 h in Caco2 cells. (A) AG490 induced a concentrationdependent decrease in proliferation. (B) Caco2 cells were incubated with various concentrations of SN38 in the presence or absence of $40 \mu \mathrm{M}$ AG490 for $48 \mathrm{~h}$. Data are expressed as percent change (means \pm SD) vs. the control. P-value vs. SN38 alone-treated cells.

\section{Discussion}

Cetuximab is a human-mouse chimeric immunoglobulin (IgG1) monoclonal antibody for EGFR that is approved for use in patients with $\mathrm{mCRC}$ and an absence of mutations in $K R A S, N R A S$ and BRAF (4-7). Some studies have shown synergistic effects of cetuximab and CPT-11 in wild-type $R A S$ and $B R A F$ mCRC patients $(4,8,9)$. It is believed that cetuximab may enhance the tumor response to CPT-11 and its active metabolite, SN38, in addition to its 'original' antitumor effects. However, the molecular mechanism of this synergistic effect has not yet been fully investigated (10-12).

HSP27 is known to be a stress-activated, adenosine triphosphate-independent cytoprotective chaperone with many notable properties, including resistance to chemotherapy in several cancers. In CRC cells, HSP27 has been reported to be a resistance factor for CPT-11, as well as a prognostic factor (24-27).

The JAK/STAT signaling pathway, and especially the transcription factor STAT3, have been implicated in the regulation of drug sensitivity $(28,29)$. In CRC cells, activated STAT3 causes resistance to CPT-11 and inhibition of STAT3 strongly enhances the cytotoxic action of CPT-11 $(30,31)$. STAT3 activation in CRC patients is associated with adverse clinical outcomes, consistent with its potential roles as a prognostic biomarker and a chemoprevention and/or therapeutic target (32). Furthermore, STAT3 has been reported to regulate HSP27 in breast epithelial cells (33). Thus, we considered that cetuximab might promote sensitivity to CPT-11 and its active metabolite, 
SN38, via suppression of the HSP27 through blocking the JAK/STAT signaling pathway.

Consistent with previous reports, HSP27 protein levels and SN38 sensitivity had a tendency to be correlated in the CRC cell lines (Fig. 1C; $\mathrm{R}=0.841, \mathrm{P}=0.159$ ) (24). Exposure to $10 \mu \mathrm{g} / \mathrm{ml}$ cetuximab and various concentrations of AG490, an inhibitor of JAK2, showed suppression of STAT3 and HSP27 protein levels except in the KRAS G12V mutant cell line, SW620. Synergistic effects of cetuximab in combination with SN38 have been confirmed only in $R A S$ wild-type and $B R A F$ wild-type cells (Caco2), and not in the three other $R A S$ - or $B R A F$-mutated cells. Furthermore, the combined effects of AG490 plus SN38 exhibited a similar tendency to that of cetuximab plus SN38, but these results were not significant in $\mathrm{Caco} 2$ cells. These results indicate that cetuximab may promote sensitivity to SN38 via suppression of HSP27, through blocking of the JAK/STAT signaling pathway in Caco2 cells. A synergistic effect was only seen at lower concentrations of SN38. The reason is uncertain; however, higher concentrations of SN38 have a strong cytotoxicity as a single agent in Caco2 cells. Therefore, the synergism with cetuximab may be masked by the strong effect of SN38.

The present study revealed two novel and important findings. First, cetuximab may cause suppression of HSP27 through blocking the JAK/STAT signaling pathway in CRC cells, because AG490 caused a concentration-dependent decrease in the level of HSP27, similar to cetuximab. This suggests that HSP27 may be a downstream mediator of the JAK/STAT signaling pathway in CRC cells. Second, suppression of HSP27 caused by cetuximab was observed even in $R A S$ - or BRAF-mutated cells (WiDR and SW480). Based on this result, it is expected that cetuximab promotes sensitivity to SN38, even in $R A S$ - or $B R A F$-mutated cells. However, no combination effect of cetuximab and SN38 was observed in RAS- or BRAF-mutated cells. The reason for this may be that suppression of HSP27 alone, through blocking of the JAK/STAT signaling pathway, did not overcome the power of the RAS/RAF signaling pathway (also known as the MAPK pathway), accelerated by the presence of $R A S$ or $B R A F$ mutations. To the best of our knowledge, there are no reports focused on the power balance of the RAS/RAF and JAK/STAT signaling pathway in CRC. We speculate that the RAS/RAF signaling pathway has a stronger potential than the JAK/STAT signaling pathway because the RAS mutation is the only proven predictive marker for anti-EGFR antibody treatments. There are no reports on similar mutations in the JAK/STAT signaling pathway in CRC (5-7,36). Furthermore, no suppression of HSP27 and STAT3 by cetuximab or AG490 was observed in SW620 cells with the KRAS G12V mutation. The reason for this is uncertain; however, a previous study reported that mutant KRAS could activate STAT3 in SW620 cells (37). Thus, SW620 may be a unique CRC cell line that does not respond to stimulation by cetuximab or AG490 in the JAK/ STAT signaling pathway.

We acknowledge several limitations of the present study. First, there is the absence of in vivo data. Secondly, we used only wild-type CRC cell lines and not CPT-11-refractory CRC cell lines. However, we used four CRC cell lines with different RAS and BRAF mutational statuses, which could affect the combination effect with cetuximab and SN38. Therefore, we believe that our data is clinically relevant. Further research is required to strengthen our hypothesis. Third, the changes in the protein levels of HSP27 and STAT3 by exposure to cetuximab or AG490 suggest that phosphorylation of HSP27 and STAT3 are also likely to gather a positive response. However, after $48 \mathrm{~h}$ of exposure to cetuximab, no changes in the phosphorylation of HSP27 and STAT3 were observed (data not shown). The reason could be that peak STAT3 phosphorylation occurs within 15-60 min in response to various stimuli, and even in the presence of a continuous cytokine, STAT3 activation decreases over several hours (38). Furthermore, HSP27 phosphorylation does not last more than several hours (39). Therefore, suppression of phosphorylated HSP27 and STAT3 was not confirmed after a 48-h exposure to cetuximab. Molecular mechanisms of the synergism between cetuximab and SN38 may be related not only to HSP27 suppression but also other factors, such as immunological effects. Recently, STAT3 inhibition can mediate anticancer effects by multiple mechanisms, including cell-autonomous effects and immunological effects (40). Cetuximab, when used in combination with FOLFIRI [one of standard chemotherapy regimens for mCRC that does no induce immunogenic cell death (ICD)], induces ICD in vitro and in vivo (41). Therefore, the molecular mechanisms of the synergism between cetuximab and SN38 potentially involve multiple mechanisms, including ICD induced by cetuximab via STAT3 inhibition, in addition to our hypothesis. A better understanding of these mechanisms will lead to novel treatments for CRC.

In conclusion, cetuximab may promote sensitivity to SN38 via suppression of HSP27 through blocking the JAK/STAT signaling pathway in RAS wild-type CRC cells.

\section{References}

1. Van Cutsem E, Köhne CH, Hitre E, Zaluski J, Chang Chien CR, Makhson A, D'Haens G, Pintér T, Lim R, Bodoky G, et al: Cetuximab and chemotherapy as initial treatment for metastatic colorectal cancer. N Engl J Med 360: 1408-1417, 2009.

2. Lièvre A, Bachet JB, Le Corre D, Boige V, Landi B, Emile JF, Côté JF, Tomasic G, Penna C, Ducreux M, et al: KRAS mutation status is predictive of response to cetuximab therapy in colorectal cancer. Cancer Res 66: 3992-3995, 2006.

3. Grávalos C, Cassinello J, Fernández-Rañada I and Holgado E: Role of tyrosine kinase inhibitors in the treatment of advanced colorectal cancer. Clin Colorectal Cancer 6: 691-699, 2007.

4. Pietrantonio F, Petrelli F, Coinu A, Di Bartolomeo M, Borgonovo K, Maggi C, Cabiddu M, Iacovelli R, Bossi I, Lonati $\mathrm{V}$, et al: Predictive role of BRAF mutations in patients with advanced colorectal cancer receiving cetuximab and panitumumab: A meta-analysis. Eur J Cancer 51: 587-594, 2015.

5. Schwartzberg LS, Rivera F, Karthaus M, Fasola G, Canon JL, Hecht JR, Yu H, Oliner KS and Go WY: PEAK: A randomized, multicenter phase II study of panitumumab plus modified fluorouracil, leucovorin, and oxaliplatin (mFOLFOX6) or bevacizumab plus mFOLFOX6 in patients with previously untreated, unresectable, wild-type KRAS exon 2 metastatic colorectal cancer. J Clin Oncol 32: 2240-2247, 2014

6. Peeters M, Oliner KS, Price TJ, Cervantes A, Sobrero AF, Ducreux M, Hotko Y, André T, Chan E, Lordick F, et al: Analysis of KRAS/NRAS mutations in a phase III study of panitumumab with FOLFIRI compared with FOLFIRI alone as second-line treatment for metastatic colorectal cancer. Clin Cancer Res 21: 5469-5479, 2015

7. Heinemann V, von Weikersthal LF, Decker T, Kiani A, VehlingKaiser U, Al-Batran SE, Heintges T, Lerchenmüller C, Kahl C, Seipelt G, et al: FOLFIRI plus cetuximab versus FOLFIRI plus bevacizumab as first-line treatment for patients with metastatic colorectal cancer (FIRE-3): A randomised, open-label, phase 3 trial. Lancet Oncol 15: 1065-1075, 2014. 
8. Meyerhardt JA and Fuchs CS: Epidermal growth factor receptor inhibitors and colorectal cancer. Oncology (Williston Park) 18 (Suppl 14): 35-38, 2004

9. Bokemeyer C, Van Cutsem E, Rougier P, Ciardiello F, Heeger S Schlichting M, Celik I and Köhne CH: Addition of cetuximab to chemotherapy as first-line treatment for KRAS wild-type metastatic colorectal cancer: Pooled analysis of the CRYSTAL and OPUS randomised clinical trials. Eur J Cancer 48: 1466-1475, 2012.

10. Sung FL, Poon TC, Hui EP, Ma BB, Liong E, To KF, Huang DP and Chan AT: Antitumor effect and enhancement of cytotoxic drug activity by cetuximab in nasopharyngeal carcinoma cells. In Vivo 19: 237-245, 2005.

11. Nakata E, Hunter N, Mason K, Fan Z, Ang KK and Milas L: C225 antiepidermal growth factor receptor antibody enhances the efficacy of docetaxel chemoradiotherapy. Int J Radiat Oncol Biol Phys 59: 1163-1173, 2004.

12. Cunningham D, Humblet Y, Siena S, Khayat D, Bleiberg H, Santoro A, Bets D, Mueser M, Harstrick A, Verslype C, et al Cetuximab monotherapy and cetuximab plus irinotecan in irinotecan-refractory metastatic colorectal cancer. N Engl J Med 351: 337-345, 2004.

13. Concannon CG, Gorman AM and Samali A: On the role of Hsp27 in regulating apoptosis. Apoptosis 8: 61-70, 2003.

14. Andrieu C, Taieb D, Baylot V, Ettinger S, Soubeyran P De-Thonel A, Nelson C, Garrido C, So A, Fazli L, et al: Heat shock protein 27 confers resistance to androgen ablation and chemotherapy in prostate cancer cells through eIF4E. Oncogene 29: 1883-1896, 2010

15. Song TF, Zhang ZF, Liu L, Yang T, Jiang J and Li P: Small interfering RNA-mediated silencing of heat shock protein 27 (HSP27) Increases chemosensitivity to paclitaxel by increasing production of reactive oxygen species in human ovarian cancer cells (HO8910). J Int Med Res 37: 1375-1388, 2009.

16. Sarto C, Valsecchi C, Magni F, Tremolada L, Arizzi C, Cordani N, Casellato S, Doro G, Favini P, Perego RA, et al: Expression of heat shock protein 27 in human renal cell carcinoma. Proteomics 4: 2252-2260, 2004

17. Ciocca DR, Fuqua SA, Lock-Lim S, Toft DO, Welch WJ and McGuire WL: Response of human breast cancer cells to heat shock and chemotherapeutic drugs. Cancer Res 52: 3648-3654, 1992.

18. Vargas-Roig LM, Gago FE, Tello O, Aznar JC and Ciocca DR Heat shock protein expression and drug resistance in breast cancer patients treated with induction chemotherapy. Int J Cancer 79: 468-475, 1998

19. Matsui Y, Hadaschik BA, Fazli L, Andersen RJ, Gleave ME and So AI: Intravesical combination treatment with antisense oligonucleotides targeting heat shock protein-27 and HTI-286 as a novel strategy for high-grade bladder cancer. Mol Cancer Ther 8: 2402-2411, 2009.

20. Hayashi R, Ishii Y, Ochiai H, Matsunaga A, Endo T, Hasegawa $H$ and Kitagawa Y: Suppression of heat shock protein 27 expression promotes 5-fluorouracil sensitivity in colon cancer cells in a xenograft model. Oncol Rep 28: 1269-1274, 2012.

21. Tsuruta M, Nishibori H, Hasegawa H, Ishii Y, Endo T, Kubota T, Kitajima M and Kitagawa Y: Heat shock protein 27, a novel regulator of 5-fluorouracil resistance in colon cancer. Oncol Rep 20: $1165-1172,2008$

22. Matsunaga A, Ishii Y, Tsuruta M, Okabayashi K, Hasegawa $H$ and Kitagawa Y: Inhibition of heat shock protein 27 phosphorylation promotes sensitivity to 5 -fluorouracil in colorectal cancer cells. Oncol Lett 8: 2496-2500, 2014.

23. Garrido C, Mehlen P, Fromentin A, Hammann A, Assem M, Arrigo AP and Chauffert B: Inconstant association between 27-kDa heat-shock protein (Hsp27) content and doxorubicin resistance in human colon cancer cells. The doxorubicin-protecting effect of Hsp27. Eur J Biochem 237: 653-659, 1996.

24. Choi DH, Ha JS, Lee WH, Song JK, Kim GY, Park JH, Cha HJ, Lee BJ and Park JW: Heat shock protein 27 is associated with irinotecan resistance in human colorectal cancer cells. FEBS Lett 581: 1649-1656, 2007.
25. Wang F, Zhang P, Shi C, Yang Y and Qin H: Immunohistochemical detection of HSP27 and hnRNP K as prognostic and predictive biomarkers for colorectal cancer. Med Oncol 29: 1780-1788, 2012.

26. Yu Z, Zhi J, Peng X, Zhong X and Xu A: Clinical significance of HSP27 expression in colorectal cancer. Mol Med Rep 3: 953-958, 2010.

27. Tweedle EM, Khattak I, Ang CW, Nedjadi T, Jenkins R, Park BK, Kalirai H, Dodson A, Azadeh B, Terlizzo M, et al: Low molecular weight heat shock protein HSP27 is a prognostic indicator in rectal cancer but not colon cancer. Gut 59: 1501-1510, 2010.

28. Bedel R, Thiery-Vuillemin A, Grandclement C, Balland J, Remy-Martin JP, Kantelip B, Pallandre JR, Pivot X, Ferrand C, Tiberghien P, et al: Novel role for STAT3 in transcriptional regulation of NK immune cell targeting receptor MICA on cancer cells. Cancer Res 71: 1615-1626, 2011.

29. Kusaba T, Nakayama T, Yamazumi K, Yakata Y, Yoshizaki A, Inoue K, Nagayasu T and Sekine I: Activation of STAT3 is a marker of poor prognosis in human colorectal cancer. Oncol Rep 15: 1445-1451, 2006

30. Weber A, Borghouts C, Delis N, Mack L, Brill B, Bernard AC, Coqueret $\mathrm{O}$ and Groner $\mathrm{B}$ : Inhibition of Stat 3 by peptide aptamer rS3-PA enhances growth suppressive effects of irinotecan on colorectal cancer cells. Horm Mol Biol Clin Investig 10: 273-279, 2012.

31. Courapied S, Sellier H, de Carné Trécesson S, Vigneron A, Bernard AC, Gamelin E, Barré B and Coqueret O: The cdk5 kinase regulates the STAT3 transcription factor to prevent DNA damage upon topoisomerase I inhibition. J Biol Chem 285: 26765-26778, 2010.

32. Morikawa T, Baba Y, Yamauchi M, Kuchiba A, Nosho K, Shima K, Tanaka N, Huttenhower C, Frank DA, Fuchs CS, et al: STAT3 expression, molecular features, inflammation patterns, and prognosis in a database of 724 colorectal cancers. Clin Cancer Res 17: 1452-1462, 2011.

33. Song H, Ethier SP, Dziubinski ML and Lin J: Stat3 modulates heat shock $27 \mathrm{kDa}$ protein expression in breast epithelial cells. Biochem Biophys Res Commun 314: 143-150, 2004.

34. Shigeta K, Hayashida T, Hoshino Y, Okabayashi K, Endo T, Ishii Y, Hasegawa $\mathrm{H}$ and Kitagawa Y: Expression of epidermal growth factor receptor detected by cetuximab indicates its efficacy to inhibit in vitro and in vivo proliferation of volorectal cancer cells. PLoS One 8: e66302, 2013.

35. Jhawer M, Goel S, Wilson AJ, Montagna C, Ling YH, Byun DS, Nasser S, Arango D, Shin J, Klampfer L, et al: PIK3CA mutation/ PTEN expression status predicts response of colon cancer cells to the epidermal growth factor receptor inhibitor cetuximab. Cancer Res 68: 1953-1961, 2008

36. Salazar R and Ciardiello F: Optimizing Anti-EGFR therapy in colorectal cancer. Clin Cancer Res 21: 5415-5416, 2015.

37. Zaanan A, Okamoto K, Kawakami H, Khazaie K, Huang $\mathrm{S}$ and Sinicrope FA: The mutant KRAS gene up-regulates BCL-XL protein via STAT3 to confer apoptosis resistance that is reversed by BIM protein induction and BCL-XL antagonism. J Biol Chem 290: 23838-23849, 2015

38. Subramaniam A, Shanmugam MK, Perumal E, Li F, Nachiyappan A, Dai X, Swamy SN, Ahn KS, Kumar AP, Tan BK, et al: Potential role of signal transducer and activator of transcription (STAT)3 signaling pathway in inflammation, survival, proliferation and invasion of hepatocellular carcinoma. Biochim Biophys Acta 1835: 46-60, 2013.

39. Stope MB, Weiss M, Preuss M, Streitbörger A, Ritter CA, Zimmermann U, Walther R and Burchardt M: Immediate and transient phosphorylation of the heat shock protein 27 initiates chemoresistance in prostate cancer cells. Oncol Rep 32: 2380-2386, 2014

40. Yang H, Yamazaki T, Pietrocola F, Zhou H, Zitvogel L, Ma Y and Kroemer G: Improvement of immunogenic chemotherapy by STAT3 inhibition. OncoImmunology 5: e1078061, 2015.

41. Pozzi C, Cuomo A, Spadoni I, Magni E, Silvola A, Conte A, Sigismund S, Ravenda PS, Bonaldi T, Zampino MG, et al: The EGFR-specific antibody cetuximab combined with chemotherapy triggers immunogenic cell death. Nat Med 22: 624-631, 2016. 